\title{
IKVAV-Containing Cell Membrane Penetrating Peptide Treatment Induces Changes in Cellular Morphology after Spinal Cord Injury
}

\author{
Soheila Kazemi ${ }^{1}$, Wendy Baltzer ${ }^{1}$, Hadi Mansouri ${ }^{2}$, Karl Schilke $^{3} \&$ John Mata $^{3}$ \\ ${ }^{1}$ Department of Clinical Sciences, USA \\ ${ }^{2}$ Biomedical Sciences, Oregon State University, College of Veterinary Medicine, USA \\ ${ }^{3}$ Department of Basic Medical Science, Western University of Health Sciences, USA \\ Correspondence: John Mata, Department of Basic Medical Sciences, College of Osteopathic Medicine - \\ Northwest, Western University of Health Sciences, Lebanon, OR 97355, USA. Tel: 1-541-259-0231. E-mail: \\ jmata@westernu.edu
}

Received: April 28, 2016

Accepted: June 24, 2016

Online Published: August 17, 2016

doi:10.5539/mas.v10n11p149

URL: http://dx.doi.org/10.5539/mas.v10n11p149

The research was partially funded through the intramural grant program in the College of Veterinary Medicine at Oregon State University.

\begin{abstract}
A cell membrane spanning peptide was used to increase the concentration of the IKVAV motif within damaged mouse spinal cord tissue. This peptide was injected directly to the lesion 24 hours after spinal cord compression injury. Because the membrane-spanning portion of the peptide adheres to tissue upon injection with a long half-life we hypothesized that the bioactive IKVAV sequence will provide a sustained regenerative signal at the sight of injury. Five different groups of mice were used and cellular morphology observations were undertaken using light and electron microscopy. Three surgical control groups: IKVAV, peptide and mannitol; one surgical treatment group: IKVAV-peptide; and one non-surgical control group: normal, were used in this experiment. In this study, treatment with IKVAV-peptide after SCI resulted in an increased number of protoplasmic astrocytes, large active motor neurons, and regeneration of muscle bundles followed by behavioral improvement. In this paper, we describe the cellular differences between all groups.
\end{abstract}

Keywords: IKVAV+peptide, neurons, protoplasmic astrocytes, muscle bundles, light micrographs, electron micrographs

\section{Introduction}

Spinal cord injury (SCI) is a debilitating condition which initiates complex cellular and molecular interactions and changes in an attempt to repair the initial tissue damage. These interactions include contributions from inflammatory cell activation, reactive astrocytes and the production of both growth- promoting and inhibitory extracellular molecules (Fitch \& Silver, 2008). The use of nanostructures in medicine is an emerging field with the potential to improve a condition or cure diseases. To assess the feasibility of using a peptide-based nanostructure that increases the concentration of the IKVAV-motif (isoleucine-lysine-valine-alanine-valine) to facilitate regeneration of damaged spinal tissue, it is necessary to compare cellular changes within the lesion site with and without treatment. Biological analysis of SCI in mouse models point to both necrotic and apoptotic mechanisms of cell death after injury (Beattie et al., 2002). Neuronal and glial apoptosis after spinal cord injury contribute to the neurological dysfunction (Liu et al., 1997).Spinal cord injury results in glial reaction, leading eventually to the formation of a glial scar. The glial scar that forms following spinal injury is an evolving structure; different cells arrive and participate in the creation of a final structure that is predominantly astrocytic. Thus the astrocyte response to injury is referred to as reactive gliosis (more glia) but in fact, in most types of injury, the actual amount of glial cell division is relatively small and confined to the immediate penumbra surrounding the lesion core (Eng, Reier, \& Houle, 1987; Reier \& Houle, 1988; Reier, 1983). Electron micrographs of neurons in gray matter have shown fragmented nucleus and condense bodies along with shrunken cell bodies (Liu et al., 1997). Following injury, skeletal muscle atrophy is a key adaptation resulting from disuse and immobilization in both complete and incomplete SCI. A few weeks post injury, skeletal muscle 
cross-sectional area (CSA) can be as low as $30 \%$ to $50 \%$ compared with able-bodied controls. Moreover, skeletal muscle atrophy has been associated with increasing infiltration of intramuscular fat (IMF) (Gorgey \& Shepherd, 2010; Wu et al., 2011; Gorgey \& Dudley, 2007). Skeletal muscle atrophy results in numerous other health-related complications (Gorgey \& Shepherd, 2010) including: altered body composition (Spungen et al., 2003); cardiovascular disease (Bauman \& Spungen, 2008); osteoporosis (Demirel et al., 1998); and increased incidence of metabolic syndrome (Nelson et al., 2007).

\section{Methods}

\subsection{Experimental Design}

All animal procedures were undertaken in accordance with the Public Health Service Policy on Human Care and Use of Laboratory Animals. All procedures were approved by the IACUC. Five groups of female Blab-c mice (10 weeks of age) were used in this study. After hemilaminectomy all groups underwent T12 spinal cord segment compression dorsoventrally by the application of a $24 \mathrm{~g}$ modified aneurysm clip for $1 \mathrm{~min}$ (Poon et al., 1976). Twenty four hours after injury, each group received different treatment: IKVAV-peptide; IKVAV; and peptide combined with mannitol. For all experiments, the experimenters were kept blind to the identity of the animals.

\subsection{Animal Tissue Acquisition and Preparation}

On the day 28, animals were euthanized with an overdose of intraperitoneal Beuthanasia-D (Schering-Plough Animal Health Corp., Union, NJ) and the spinal cords were removed and immediately placed in $2 \%$ buffered formalin. The spinal cords were kept at $4^{\circ} \mathrm{C}$ overnight and transferred to the Karnovsky fixative (J 1965) before placing at $4^{\circ} \mathrm{C}$ for 3 hours. Four sodium cacodylate buffer rinses were done at 30 minute intervals and the specimens were transferred into osmium tetroxide $\left(\mathrm{OsO}_{4}\right)$ for $1 \mathrm{hr}$ at $25^{\circ} \mathrm{C}$. The dehydration procedures were done using $50 \%$ acetone, $70 \%$ acetone twice and $100 \%$ acetone each for 30 minutes respectively. After dehydration, the spinal cords were infiltrated using acetone: Spurr's resin mixture (first with a proportion of 3:1 for 30 minutes) following by 1:1 and 1:3 each for one hour and then $100 \%$ Spurr's overnight on a rotator. After 24 hours, each spinal cord was embedded in the flat mound and kept at $63{ }^{\circ} \mathrm{C}$ overnight. Semi-thin sections $(0.5 \mu)$ were cut using a Sorvall MT2-b for light microscopic observations and then $(60 \mathrm{~nm})$ ultrathin sections were cut with a diamond knife and put on 100 mesh copper grids for transmission electron microscopic study using Philips CM/12 STEM.

\subsection{Muscle Preparation}

Upper hind limb muscles were dissected from all groups and fixed in $10 \%$ buffered formalin and processed routinely for light microscopic evaluations.

\subsection{Neuron and Muscle Size Quantification}

The computer software ImageJ was used to measure the neuron and muscle size using their images. We used $\mu \mathrm{m}$ as a unit for measuring the surface of each neuron and each muscle bundle.

\subsection{Protoplasmic Astrocytes Quantification}

Astrocytes were counted in 3 fields of each semithin section for each mouse using calibrated ocular lens with Lattice lines.

\section{Results}

Light microscopic observations using semi-thin sections revealed that the main morphological difference between IKVAV-peptide treated mice and other three groups was the size of the motor neurons. It was interesting to observe that IKVAV-peptide treated mice had neurons even larger than the normal group. In comparison to the IKVAV-peptide treated group, the other three control groups had smaller than normal neurons with shrunken cell cytoplasm. Between the three surgical control groups, peptide group had completely shrunken neurons, however, mannitol and IKVAV both had only very small neurons (Figures 1-2). At the electron microscopic level, a survey of ultrathin sections revealed that, in the IKVAV-peptide group, all the motor neurons were active consisting of active cytoplasmic organelles such as extensive rough endoplasmic reticulum (RER), free ribosome, developed Golgi complex and mitochondria surrounding euchromatic nucleus (Fig. 3B). These ultrastructural characteristics were similar in appearance to the control untreated group (Normal) (Fig. 3A), however, IKVAV-peptide treated neurons were much larger and active confirming observations made at the light microscopic level. In treated control groups, motor neurons were nonactive with shrunken cytoplasm having dispersed segmented RER and loosely associated nuclear chromatin in their nuclei (Fig. 4). Particularly in all treated control groups the nuclear membranes were not folded compare with normal and IKVAV-peptide treated groups (Fig. 3A \& B) and the outer nuclear membrane lacked ribosomal attachments in most areas. 
In this experiment, counting the number of protoplasmic astrocytes in each group after 4 weeks of study demonstrated that the IKVAV-peptide treated mice had more protoplasmic astrocytes surrounding the motor neurons compared to the normal untreated, mannitol and IKVAV groups. However, the protoplasmic astrocytes were almost the same in number in both IKVAV-peptide and peptide groups. Observations on the upper hind limb muscles revealed that in IKVAV-peptide treated group, muscle bundles were thicker in comparison to IKVAV, peptide, and mannitol groups but not with normal groups. In addition, the intramuscular fat, which was also seen between bundles, occupied fewer regions in IKVAV-peptide group than others (Fig. 5).

\section{Discussion}

In this study, the laminin-derived IKVAV sequence has been incorporated into protoplasmic astrocytes in order to enhance neural attachment, migration and neurite outgrowth (Kikukawa et al., 1998).To explore the cellular changes related to this improvement, light and electron microscopic evaluation of neurons, protoplasmic astrocytes and muscle bundles were undertaken. Findings included that IKVAV-peptide treatment resulted in neurite reactivation in gray matter, evinced by functional improvement using the modified BBB locomotion score scale (data not shown) and morphological changes that demonstrated the slow but impressive functional progress after SCI. Neuronal death is normal during nervous system development but it is an abnormal consequence of brain and spinal cord injury with two distinct forms of cell death, apoptosis and necrosis (Mahoney et al., 2005). Microscopic observations of the neurons within the lesion sites produced in this study, is consistent with other studies, which have described apoptosis and necrotic death after spinal cord injury (Liu et al., 1997). In the present study, reactivation of neurons with euchromatic nucleus, presence of extensive RER, free ribosomes and many mitochondria seen in IKVAV-peptide treated group in comparison to other three control treated groups (IKVAV, peptide, mannitol) was clearly evident. It has been previously observed that the absence of astrocytes in both white and gray matter results in unsuccessful axon regeneration. The presence of immature fibrous astrocytes in the white matter and reactive protoplasmic astrocytes in the gray matter of the spinal cord within the injury site in the early post-injury phase are necessary for axon regeneration (Shibuya, Yamamoto \& Itano, 2009; Kikukawa et al., 1998; Inoue, Kawaguchi, \& Kurisu, 1998). Protoplasmic astrocyte enumeration in the IKVAV-peptide group demonstrated an increased number compared to all groups including the normal nonsurgical group. This suggests that, in the subacute phase, the existence of astrocytes is necessary for reactivation of neurons and subsequently regeneration of axons and their absence can markedly exacerbate neuron and glial cell degeneration. These results are also consistent with other studies (Faulkner et al., 2004; Okada et al., 2006; Bush et al., 1999; McDonald et al., 1998). Successful spinal cord therapies have been shown to correlate with reduced atrophy and muscle rebuilding (Mahoney et al., 2005; Adams et al., 2004; Gorgey \& Shepherd, 2010). Both functional improvement was observed in IKVAV-peptide treated mice as well as confirmation at the microscopic level that revealed increases in the muscle bundle mass and decreased intramuscular fat.

\section{Conclusions}

To study the effects of the IKVAV-peptide treatment, a matrix of treatment and control groups of mice were blinded to investigators to evaluate the effects of this novel nanostructure and assess efficacy under microscopic and sub-microscopic level. Our findings demonstrate that IKVAV-peptide improves the functional behavior of cells within spinal cord injury since it promoted neurite reactivation and function. The neurons in IKVAV-peptide group became more active presumably to compensate for deficits following injury as evinced by more functional organelles compared to all groups including neurons found in normal spinal cord tissue. Notably, mice in IKVAV-peptide group showed an improvement in their life quality by being more conscious, active and healthier than mice in other groups. These findings revealed that a peptide that includes a cell spanning moiety and the neurite-stimulating motif IKVAV is a unique structure that has the potential to treat and improve the quality of life among patients with SCI. However, these results are preliminary and this research would benefit from larger numbers of animals and longer duration to assess a more complete understanding of the applications and limitations of this technology. Therefore, further investigation is warranted to evaluate the full potential of this treatment approach in SCI and other conditions where peptide mediated regeneration is possible. 

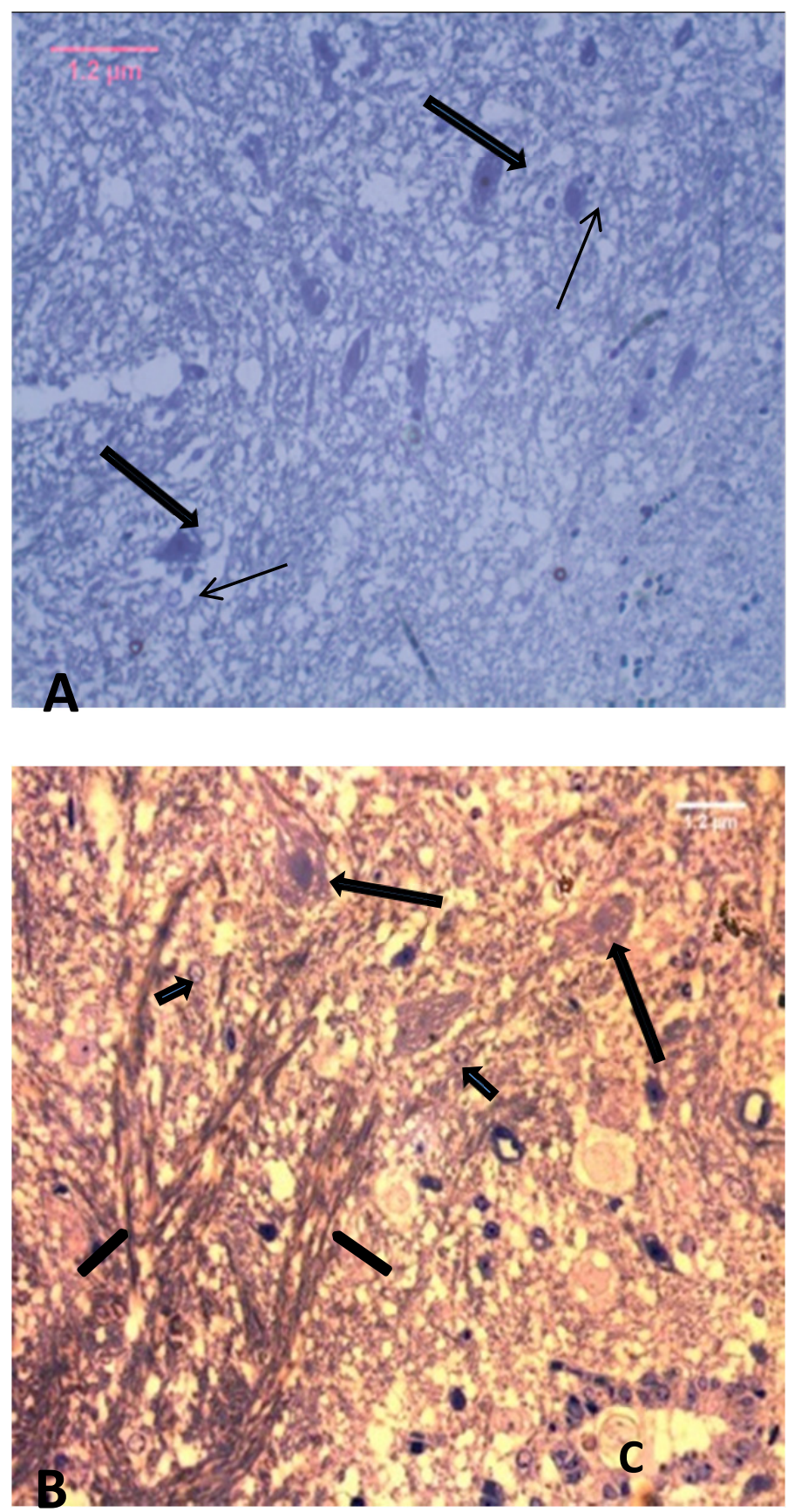

Figure 1.

Note. (A) Photomicrograph of untreated normal mouse showing a portion of ventral horn of gray matter. A few relatively large motor neurons with pale nuclei and dark nucleoli (large arrows) can be seen between cellular processes. Protoplasmic astrocytes are also evident (small arrows). (B) Photomicrograph of IKVAV+peptide treated mouse revealing very large active motor neurons (large arrows) surrounded by many nerve fibers (small arrows). Many protoplasmic astrocytes are visible (smallest arrows). A cross section of spinal canal lining by large cuboidal cells can also be seen (C). Toluidine Blue X400. 

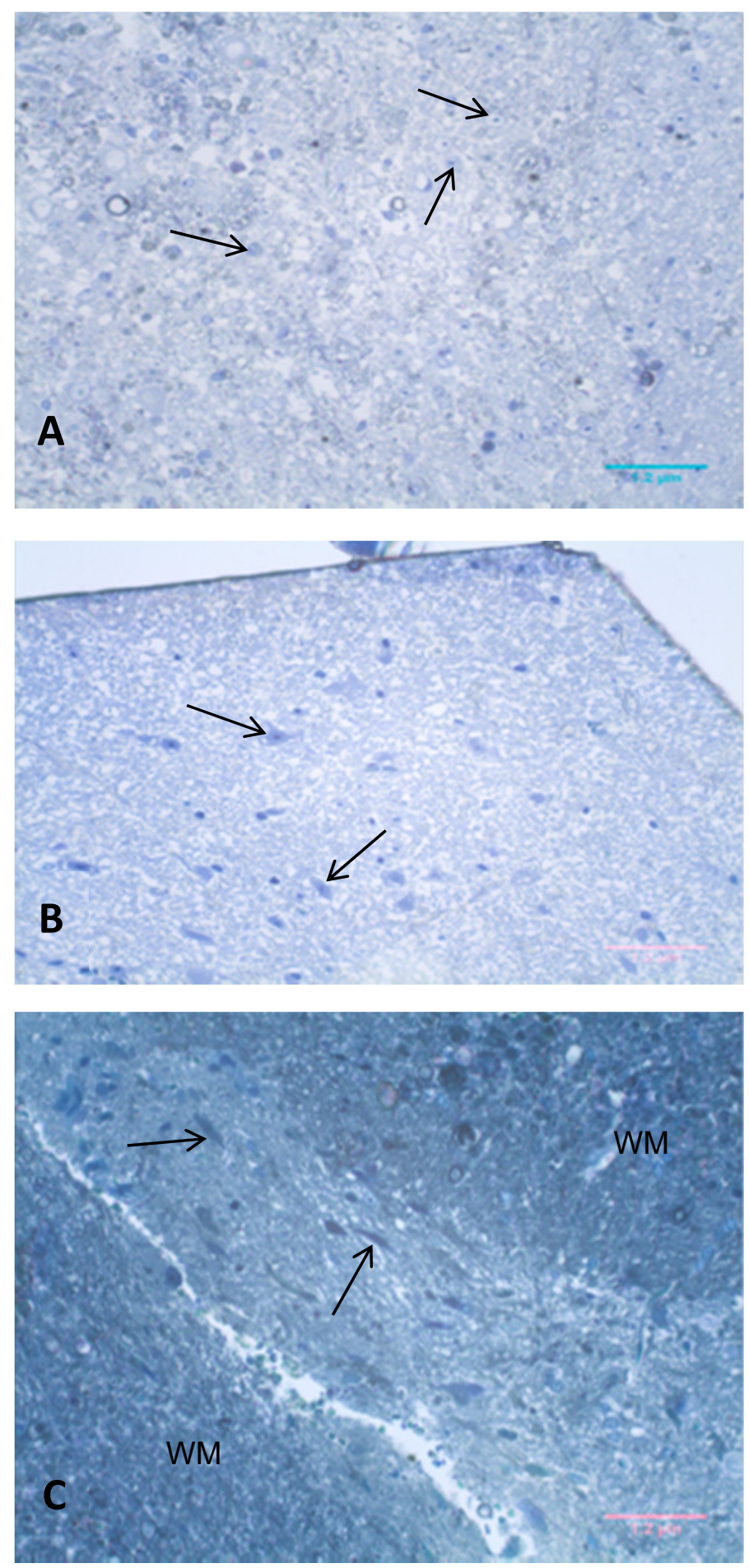

Figure 2.

Note. (A) In photomicrograph of peptide treated control mouse, most of the motor neurons are atrophied (arrows). (B) Photomicrograph showing only the gray matter portion of the spinal cord in mannitol treated control mouse. All motor neurons are again atrophied (arrows). (C) Photomicrograph shows a portion of ventral horn of gray matter between white matter (WM) from IKVAV treated control mouse. Note the atrophied motor neurons (arrows). Compare these sections with figures 1A\&2B (normal and IKVAV+peptide). Toluidine Blue $\mathrm{X} 400$. 

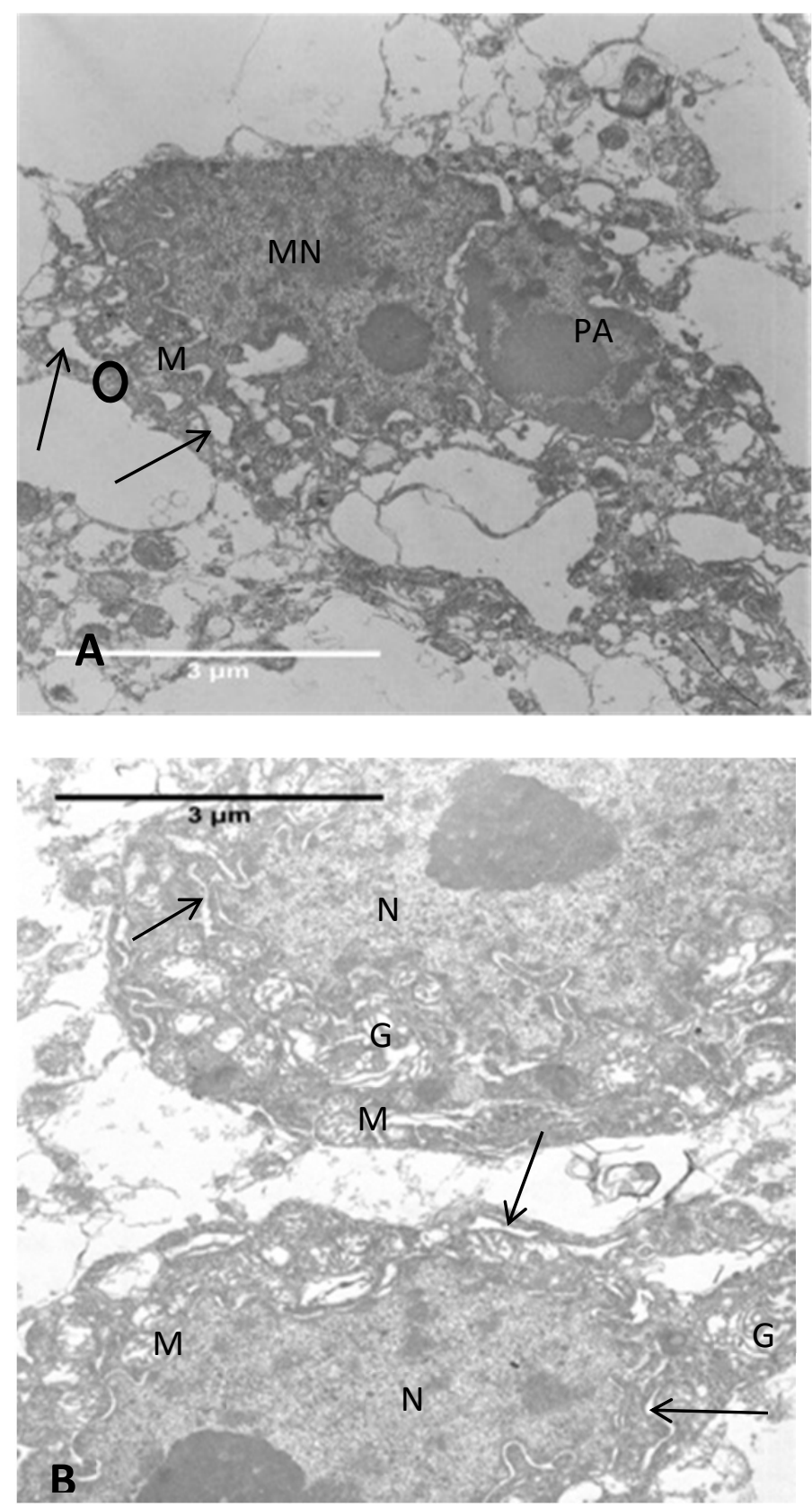

Figure 3.

Note. Electron micrograph of untreated normal mouse (A). In this micrograph, a protoplasmic astrocyte (PA) can be seen in close association with a motor neuron (MN). Motor neuron has relatively a large euchromatic nucleus with prominent dense nucleolus surrounded by small portion of cytoplasm rich in Nissl substances, RER at arrows and free ribosomes (Circle). A few mitochondria (M) can also be seen. Uranyl acetate and lead citrate X7100. Electron micrograph of IKVAV+peptide treated mouse (B). Two active motor neurons can be seen, each with large euchromatic nucleus (N) and prominent electron dense nucleolus. Many cisternae of RER (arrows), active Golgi complexes $(\mathrm{G})$ and mitochondria (M) are also evident throughout the perikaryon. Note the highly folded nuclear membranes in both cells. Compared to untreated normal mouse (A), these motor neurons are much larger. Uranyl acetate and lead citrate X7100. 

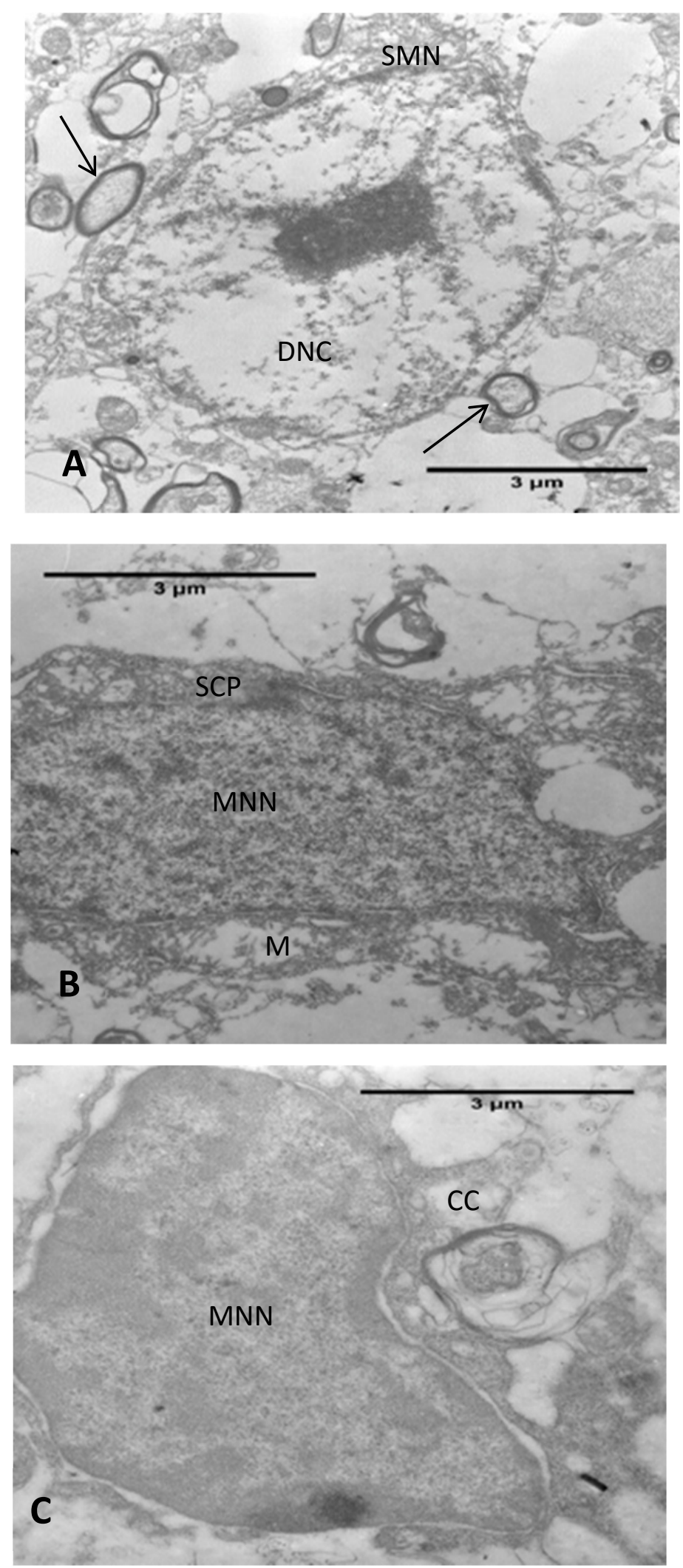

Figure 4.

Note. Electron micrograph from peptide treated control mouse (A) shows obviously a shrunken motor neuron (SMN) with dispersed nuclear chromatin (DNC). Few myelinated nerve fibers (arrows) can also be seen. Uranyl acetate and lead citrate X7100. Electron micrograph of motor neuron in mannitol treated mouse (B) revealing another atrophied neuron. The small cytoplasmic portion (SCP) is mostly occupied by degenerated mitochondria 
(M). Uranyl acetate and leas citrate X8800. Electron micrograph of a shrunken motor neuron of IKVAV treated control mouse (C). Even at this magnification the cellular cytoplasm (CC) is not apparent. Uranyl acetate and lead citrate X15000. Note the lack of nuclear membrane infolding in all control groups.
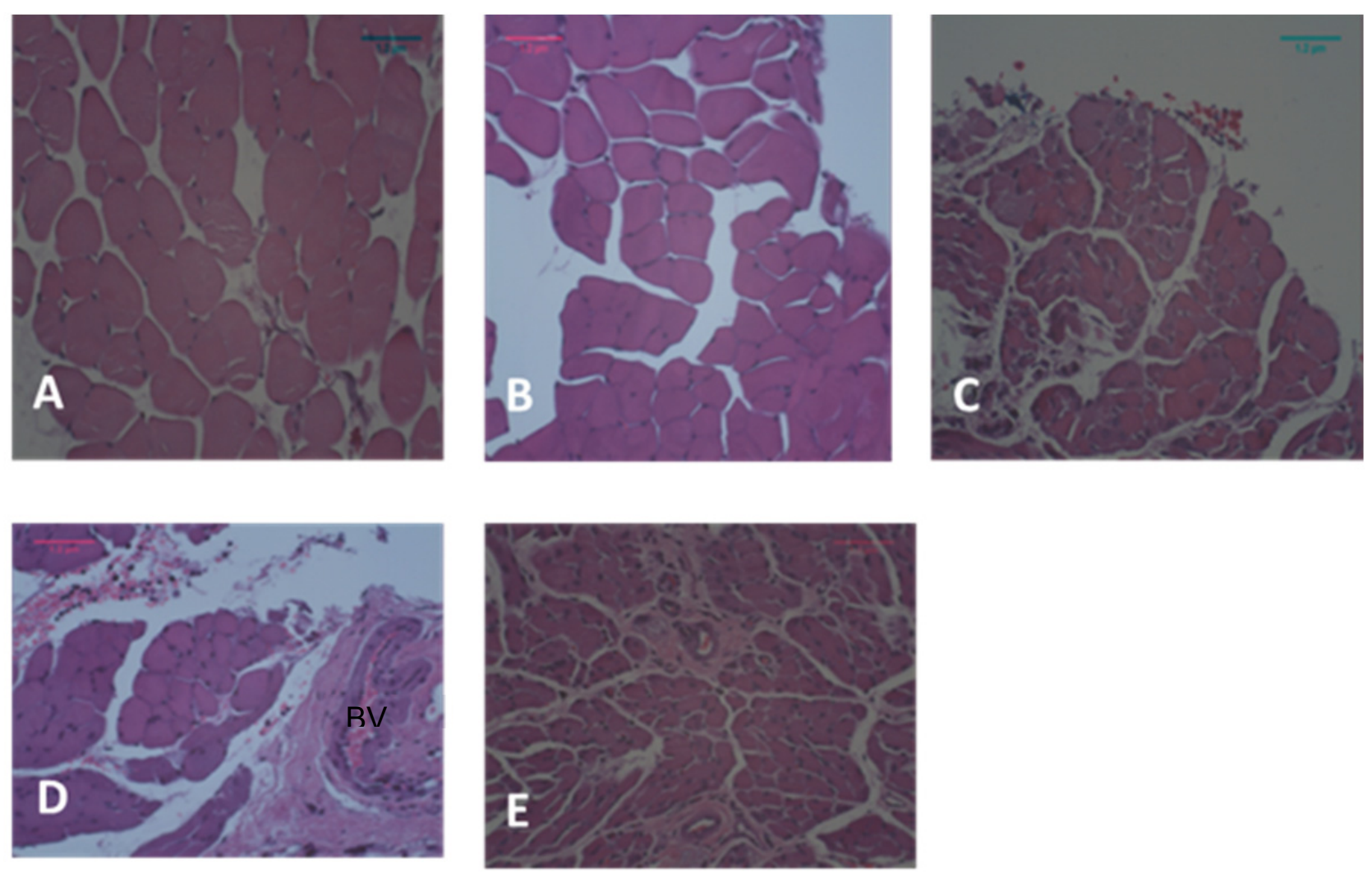

Figure 5.

Note. Comparative photomicrographs showing cross sections of the hind limb muscle in different groups, normal (A), IKVAV+peptide (B), IKVAV (C), mannitol (D), peptide (E) of mice at the same magnification. Note the presence of thicker bundles in IKVAV+peptide group compared to the other control groups. Blood vessel (BV). $\mathrm{H} \& \mathrm{E}, \mathrm{X} 400$.

\section{Acknowledgement}

The authors would like to acknowledge the Electron Microscopy facility and team at Oregon State University for their assistance with our project.

\section{References}

Adams, G. R., Cheng, D. C., Haddad, F., \& Baldwin, K. M. (2004). Skeletal muscle hypertrophy in response to isometric, lengthening, and shortening training bouts of equivalent duration. Journal of Applied Physiology, 96, 1613-8. Retrieved from http://www.ncbi.nlm.nih.gov/pubmed/15075307

Bauman, W. A., \& Spungen, A. M. (2008). Coronary heart disease in individuals with spinal cord injury: assessment of risk factors. Spinal Cord, 46, 466-76. Retrieved from http://www.ncbi.nlm.nih.gov/pubmed/18180789

Beattie, M. S., Hermann, G. E., Rogers, R. C., \& Bresnahan, J. C. (2002). Cell death in models of spinal cord injury. Progress in Brain Research, 137, 37-47. Retrieved from http://www.ncbi.nlm.nih.gov/pubmed/12440358

Bush, T. G., Puvanachandra, N., Horner, C. H., Polito, A., Ostenfeld, T., Svendsen, C. N., ... Sofroniew, M. V. (1999). Leukocyte infiltration, neuronal degeneration, and neurite outgrowth after ablation of scar-forming, reactive astrocytes in adult transgenic mice. Neuron, 23, 297-308. Retrieved from http://www.ncbi.nlm.nih.gov/pubmed/10399936 
Demirel, G., Yilmaz, H., Paker, N., \& Onel, S. (1998). Osteoporosis after spinal cord injury. Spinal Cord, 36, 822-5. Retrieved from http://www.ncbi.nlm.nih.gov/pubmed/9881730

Eng, L. F., Reier, P. J., \& Houle, J. D. (1987). Astrocyte activation and fibrous gliosis: glial fibrillary acidic protein immunostaining of astrocytes following intraspinal cord grafting of fetal CNS tissue. Progress in Brain Research, 71, 439-55. Retrieved from http://www.ncbi.nlm.nih.gov/pubmed/3588961

Faulkner, J. R., Herrmann, J. E., Woo, M. J., Tansey, K. E., Doan, N. B., \& Sofroniew, M. V. (2004). Reactive astrocytes protect tissue and preserve function after spinal cord injury. Journal of Neuroscience, 24, 2143-55. Retrieved from http://www.ncbi.nlm.nih.gov/pubmed/14999065

Fitch, M. T., \& Silver, J. (2008). CNS injury, glial scars, and inflammation: Inhibitory extracellular matrices and regeneration failure. Experimental Neurology, 209, 294-301. Retrieved from http://www.ncbi.nlm.nih.gov/pubmed/17617407

Gorgey, A. S., \& Dudley, G. A. (2007). Skeletal muscle atrophy and increased intramuscular fat after incomplete spinal cord injury. Spinal Cord, 45, 304-9. Retrieved from http:/www.ncbi.nlm.nih.gov/pubmed/16940987

Gorgey, A. S., \& Shepherd, C. (2010). Skeletal muscle hypertrophy and decreased intramuscular fat after unilateral resistance training in spinal cord injury: case report. Journal of Spinal Cord Medicine, 33, 90-5. http://www.ncbi.nlm.nih.gov/pubmed/20397451

Inoue, T., Kawaguchi, S., \& Kurisu, K. (1998). Spontaneous regeneration of the pyramidal tract after transection in young rats. Neuroscience Letters, 247, 151-4. Retrieved from http://www.ncbi.nlm.nih.gov/pubmed/9655615

Karnovsky, M. J. (1965). A formaldehyde-glutaraldehyde fixative of high osmolality for use in electron microscopy. Cell Biol., 27, 137.

Kikukawa, S., Kawaguchi, S., Mizoguchi, A., Ide, C., \& Koshinaga, M. (1998). Regeneration of dorsal column axons after spinal cord injury in young rats. Neuroscience Letters, 249, 135-8. Retrieved from http://www.ncbi.nlm.nih.gov/pubmed/9682835

Liu, X. Z., Xu, X. M., Hu, R., Du, C., Zhang, S. X., McDonald, J. W., .. Choi, D. W. (1997). Neuronal and glial apoptosis after traumatic spinal cord injury. Journal of Neuroscience, 17, 5395-406. Retrieved from http://www.ncbi.nlm.nih.gov/pubmed/9204923

Mahoney, E. T., Bickel, C. S., Elder, C., Black, C., Slade, J. M., Apple, D. Jr., \& Dudley, G. A. (2005). Changes in skeletal muscle size and glucose tolerance with electrically stimulated resistance training in subjects with chronic spinal cord injury. Archives of Physical Medicine and Rehabilitation, 86, 1502-4. Retrieved from http://www.ncbi.nlm.nih.gov/pubmed/16003691

McDonald, J. W., Althomsons, S. P., Hyrc, K. L., Choi, D. W., \& Goldberg, M. P. (1998). Oligodendrocytes from forebrain are highly vulnerable to AMPA/kainate receptor-mediated excitotoxicity. Nature Medicine, 4, 291-7. Retrieved from http://www.ncbi.nlm.nih.gov/pubmed/9500601

Nelson, M. D., Widman, L. M., Abresch, R. T., Stanhope, K., Havel, P. J., Styne, D. M., \& McDonald, C. M. (2007). Metabolic syndrome in adolescents with spinal cord dysfunction. Journal of Spinal Cord Medicine, 30, S127-39. Retrieved from http://www.ncbi.nlm.nih.gov/pubmed/17874698

Okada, S., Nakamura, M., Katoh, H., Miyao, T., Shimazaki, T., Ishii, K., ...Okano, H. (2006). Conditional ablation of Stat3 or Socs3 discloses a dual role for reactive astrocytes after spinal cord injury. Nature Medicine, 12, 829-34. Retrieved from http://www.ncbi.nlm.nih.gov/pubmed/16783372

Poon, P. C., Gupta, D., Shoichet, M. S., \& Tator, C. H. (1976). Clip compression model is useful for thoracic spinal cord injuries: histologic and functional correlates. Spine, 32, 2853-9.

Reier, P. J. (1983). The astrocytic scar as an impediment to regeneration in the central nervous system. In Kao, C. C., Bunge, R. P., \& Reier, P. J. (Eds.), Spinal cord reconstruction (pp. 163-195). Raven Press, New York.

Reier, P. J., \& Houle, J. D. (1988). The glial scar: its bearing on axonal elongation and transplantation approaches to CNS repair. Advances in Neurology, 47, 87-138. Retrieved from http://www.ncbi.nlm.nih.gov/pubmed/3278533

Shibuya, S., Yamamoto, T., \& Itano, T. (2009). Glial and axonal regeneration following spinal cord injury. Cell Adh. Migr., 3, 99-106. Retrieved from http://www.ncbi.nlm.nih.gov/pubmed/19372750

Spungen, A. M., Adkins, R. H., Stewart, C. A., Wang, J., Pierson, R. N. Jr., Waters, R. L., \& Bauman, W. A. 
(2003). Factors influencing body composition in persons with spinal cord injury: a cross-sectional study. Journal of Applied Physiology, 95, 2398-407. $\quad$ Retrieved from http://www.ncbi.nlm.nih.gov/pubmed/12909613

Wu, Y., Zhao, J., Zhao, W., Pan, J., Bauman, W. A., \& Cardozo, C. (2012). Nandrolone normalizes determinants of muscle mass and fiber type after SCI. Journal of Neurotrauma, 29(8), 1663-1675. http://dx.doi.org/10.1089/neu.2011.2203

\section{Copyrights}

Copyright for this article is retained by the author(s), with first publication rights granted to the journal.

This is an open-access article distributed under the terms and conditions of the Creative Commons Attribution license (http://creativecommons.org/licenses/by/4.0/). 